\title{
Características físico-químicas e citológicas do líquido sinovial da bainha tendínea digital de eqüinos
}

[Physical, biochemical and cytological characteristics of the equine digital flexor tendon sheath synovial fluid]

\author{
P.A. Barnabe ${ }^{1}$, J.W. Cattelan ${ }^{2} *$ F.A. Cadioli ${ }^{1}$, R.F. Godoy ${ }^{1}$ \\ ${ }^{1}$ Doutorando - FCAV - UNESP-Jaboticabal, SP \\ ${ }^{2}$ Departamento de Clínica e Cirurgia Veterinárias - FCAV - UNESP \\ Via de Acesso Prof. Paulo Donato Castellane, km 5 \\ 14884-900 - Jaboticabal, SP
}

\begin{abstract}
RESUMO
Foram estudadas as características físico-químicas e citológicas do líquido sinovial da bainha tendínea digital de nove eqüinos hígidos. Verificou-se que o líquido é viscoso, amarelo claro, límpido, livre de partículas e que não coagula à temperatura ambiente. Sua concentração média de ácido hialurônico foi $60,20 \mathrm{mg} / \mathrm{dl}$, a taxa de glicose, similar à plasmática e sua concentração protéica não ultrapassou $1,74 \mathrm{~g} / \mathrm{dl}$, com relação média albumina:globulina de 0,94. O número médio de células nucleadas foi de 313 células/ $\mu 1$, com predominância de grandes células mononucleares e linfócitos. Houve correlação significativa $(\mathrm{r}=-0,649, \mathrm{P}<0,01)$ entre o aumento da concentração de ácido hialurônico e a diminuição percentual de linfócitos. As mensurações das características pesquisadas no líquido sinovial da bainha tendínea digital de eqüinos são de execução simples e passíveis de implantação na rotina de atendimentos clínico-cirúrgicos.
\end{abstract}

Palavras-chave: eqüino, líquido sinovial, bainha tendínea digital

\begin{abstract}
Physical, biochemical and cytological characteristics of the digital flexor tendon sheath synovial fluid were studied in nine clinically normal horses. It is a viscous, pale yellow, clear fluid, without flocculent material and does not clot at room temperature. Its hyaluronic acid mean concentration was 60.20mg/dL, glucose levels were similar to the plasmatic levels, and its protein concentration was up to $1.74 \mathrm{~g} / \mathrm{dL}$, with mean albumin:globulin ratio of 0.94. Nucleated cells mean number was 313 cells/ $\mu L$, with predominating large mononuclear cells and lymphocytes. There was a significant correlation $(r=-0.649, P<0.01)$ between increasing hyaluronic acid concentration and decreasing lymphocyte counts. Equine digital tendon sheath synovial fluids can be easily evaluated, being feasible in clinical and surgical routine, and the information may be useful to the diagnosis, treatment and prognosis of animals with tendon sheath associated lesions.
\end{abstract}

Keywords: equine, synovial fluid, digital tendon sheath

Recebido para publicação em 26 de março de 2004

Recebido para publicação, após modificações, em 22 de setembro de 2004

${ }^{*}$ Autor para correspondência (corresponding author)

E-mail: cattelan@fcav.unesp.br 


\section{INTRODUÇÃO}

O líquido sinovial (LS) existente nas cavidades articulares e bainhas tendíneas (BTs) pode ser considerado um fluido especializado que reflete alterações no tecido sinovial (Van Pelt, 1962) e no metabolismo intra-articular ocasionadas pela doença (Van Pelt, 1962; 1974). Informações obtidas pela análise do fluido podem indicar a natureza e a extensão das lesões intra-articulares e contribuir com outras técnicas auxiliares na determinação do diagnóstico, na definição do tratamento (Tew e Hotchkiss, 1981) e no seu acompanhamento (Moyer, 1983), possibilitando estabelecer prognóstico fidedigno (Tew e Hotchkiss, 1981). Esses princípios também são aplicáveis à análise do LS das BTs (Barnabé, 2001).

Nos eqüinos, a infecção da BT é uma condição crítica devido à severa claudicação que produz, às dificuldades na cura da infecção das estruturas sinoviais e às seqüelas que podem produzir claudicações crônicas (Bertone, 1995). A bainha tendínea digital (BTD) é a mais comumente afetada (Honnas et al., 1991; Bertone, 1995). As enfermidades dessa bainha são freqüentes nos cavalos atletas (Malark et al., 1991), podendo limitar severa e permanentemente o desempenho atlético desses (Honnas et al., 1991).

O prognóstico e o sucesso no tratamento da tenossinovite estão diretamente relacionados ao seu diagnóstico precoce (Barnabé et al., 2004) e, apesar de a ultra-sonografia fornecer dados sobre a extensão da lesão, informações adicionais em casos de difícil diagnóstico podem ser obtidas pela avaliação do LS da bainha digital (Malark et al., 1991), sendo necessário o conhecimento de seus valores normais para viabilizar a interpretação das amostras alteradas (Barnabé et al., 2004). Sabese também que alguns laboratórios de análise apresentam variações no que consideram valores normais ou patológicos para esse fluido (Trotter e McIlwraith, 1996), encorajando a pesquisa de valores de referência para o LS das BTs. Assim, o objetivo deste estudo foi analisar as características físicas, químicas e citológicas do líquido sinovial da bainha tendínea digital de eqüinos hígidos.

\section{MATERIAL E MÉTODOS}

Foram utilizados nove eqüinos sem raça definida, machos, adultos e hígidos, selecionados com base na inexistência de doença sistêmica e de histórico de doença musculoesquelética, ausência de claudicação e quaisquer alterações ou dor evidenciadas à palpação dos tendões flexores digitais ou de suas bainhas. $\mathrm{Na}$ véspera da colheita do LS, os animais foram submetidos a jejum alimentar e hídrico de nove horas.

Imediatamente antes da administração da medicação pré-anestésica, foram colhidas amostras de sangue da jugular para dosagens bioquímicas da glicemia, concentrações de proteínas totais, albumina, globulinas, relação albumina:globulina e atividades enzimáticas da fosfatase alcalina (FA) e da aspartato aminotransferase (AST). Em seguida, foram feitas a lavagem dos membros, a tricotomia e a higienização da área a ser puncionada.

Os animais, submetidos à anestesia geral, foram mantidos em decúbito lateral durante a colheita das amostras de LS. Aplicou-se bandagem elástica compressiva em cada membro mantido em extensão, envolvendo-o próximo-distalmente desde a região média do metacarpo/metatarso até abaixo da articulação metacarpo/metatarsofalangeana (boleto), conforme descrito por Malark et al. (1991). A região a ser puncionada foi submetida à anti-sepsia de rotina. Os tendões flexores do dedo foram localizados por palpação e, dorsalmente a eles, inseriu-se uma agulha hipodérmica 40×12mm na bainha digital, no terço médio da quartela. Com auxílio de seringa de polietileno de $10 \mathrm{ml}$, aspirou-se todo o LS possível. A punção foi realizada nos quatro membros de cada animal.

$\mathrm{O}$ aspecto, o volume total de fluido e a viscosidade foram anotados no momento da colheita de cada amostra, que então foi dividida em duas alíquotas, uma contendo solução de EDTA a $10 \%$. Na alíquota sem EDTA foi pesquisada a ocorrência de coagulação. As alíquotas foram enviadas imediatamente ao laboratório onde, com exceção da fração de LS destinada às contagens celulares totais e diferencial de células nucleadas $(\mathrm{CN})$, passaram por centrifugação a $1500 \mathrm{~g}$ por cinco minutos, sendo utilizadas para determinação da densidade, qualidade do precipitado de mucina 
(QPM) e mensuração dos conteúdos de glicose, ácido hialurônico (AH), proteínas totais, albumina, globulinas, cálculo da relação albumina:globulina (A:G) e quantificação das atividades da FA e da AST.

A determinação da viscosidade foi realizada no momento da transferência do LS da seringa de colheita para os tubos de ensaio, estimando-se o comprimento, em centímetros, do filamento formado pela gota antes de se desprender de seu bico. Considerou-se viscosidade diminuída quando o comprimento do filamento foi inferior a $5 \mathrm{~cm}$. Às características encontradas foram atribuídos escores numéricos (diminuída $=1$, normal $=2$ ) para posterior análise estatística.

A formação de coágulo foi avaliada visualmente na alíquota de LS sem EDTA acondicionada em tubo de ensaio. A densidade do LS foi determinada por refratometria e a qualidade do precipitado de mucina pela qualidade do coágulo formado após adição de ácido acético ao LS. Os coágulos obtidos foram classificados segundo Van Pelt (1967), atribuindo-lhes escores numéricos (bom $=3$, regular $=2$, ruim $=$ 1 e muito ruim $=0$ ) para posterior análise estatística.

Para a determinação das concentrações de glicose plasmática e sinovial, empregou-se a espectrofotometria, pelo método de Bondar e Mead modificado ${ }^{1}$; para a concentração de ácido hialurônico, usou-se a colorimetria empregandose $100 \mu \mathrm{l}$ do $\mathrm{LS}$, método de precipitação por Alcian Blue, modificado por Little et al. (1990). Soluções purificadas de ácido hialurônico ${ }^{2}$ com diferentes concentrações foram usadas como padrão (Little et al., 1990).

A concentração sérica das proteínas totais foi determinada pelo método do biureto $^{3}$ e a do LS, pelo método de Bradford (1976) em $5 \mu \mathrm{l}$ da amostra, utilizando como padrão soluções purificadas de albumina sérica bovina ${ }^{4}$. As determinações das concentrações séricas e sinoviais de albumina foram realizadas

${ }^{1}$ Kit Glicose HK - Labtest Diagnóstica S.A.- Lagoa Santa MG.

2 Hylartil Vet - Pharmacia \& Upjohn AB - Uppsala Sweden.

3 Kit Proteínas Totais - Labtest Diagnóstica S.A.- Lagoa Santa-MG.

${ }^{4}$ Sigma Chemical Co - St. Louis - MO - USA. colorimetricamente pelo método do verde de bromocresol $^{5}$. Foram calculadas as concentrações de globulinas e a relação A:G no soro e no LS.

$\mathrm{Na}$ determinação das atividades enzimáticas sérica e sinovial da FA, usou-se o método de Bowers e McComb modificado ${ }^{6}$ e, na da AST, o método cinético $\mathrm{UV}^{7}$.

Para as características citológicas do LS, as contagens globais de hemácias e $\mathrm{CN}$ foram realizadas com hematocitômetro de Neubauer. As contagens diferenciais de $\mathrm{CN}$ foram realizadas em lâminas coradas com mistura de metanol, May-Grünwald e Giemsa. Foram contadas 100 células nucleadas de cada lâmina, sendo classificadas como linfócitos, grandes células mononucleares, neutrófilos segmentados e eosinófilos. As grandes células mononucleares constituíram-se de monócitos, macrófagos e eventuais células da membrana sinovial (Mahaffey, 1992; Parry, 1999).

Os dados foram submetidos à análise de variância para comparações entre os membros torácicos e pélvicos. Características subjetivas como viscosidade e QPM, para as quais se atribuíram escores numéricos, foram estudadas, empregando-se análise de variância não paramétrica, utilizando-se o teste de KruskalWallis. O coeficiente de correlação de Pearson foi aplicado para estudar a correlação entre as variáveis pesquisadas no LS, bem como para associar algumas delas com sua correspondente sangüínea. Todas as análises foram realizadas utilizando-se o programa SAS System 6.12, sendo considerado o nível de significância de $\mathrm{P} \leq 0,05$.

\section{RESULTADOS E DISCUSSÃO}

Os valores obtidos (média \pm erro padrão) no sangue para glicemia $(92,73 \mathrm{mg} / \mathrm{dl} \pm 3,05)$, proteínas totais $(7,13 \mathrm{~g} / \mathrm{dl} \pm 0,18)$, relação $\mathrm{A}: \mathrm{G}$ $(0,74 \pm 0,07)$ e atividades enzimáticas séricas da FA $(251,54 \mathrm{U} / 1 \pm 17,81)$ e da AST

\footnotetext{
${ }^{5}$ Kit Albumina - Labtest Diagnóstica S.A.- Lagoa Santa $\mathrm{MG}$.

${ }^{6}$ Kit Fosfatase Alcalina PNP - Labtest Diagnóstica S.A.Lagoa Santa - MG.

${ }^{7}$ Kit AST/ GOT - Labtest Diagnóstica S.A. - Lagoa Santa MG.
} 
$(252,60 \mathrm{U} / \mathrm{ml} \pm 31,68)$ encontram-se dentro dos limites de normalidade para a espécie eqüina segundo Kaneko et al. (1997).

Não houve diferenças significativas $(\mathrm{P}>0,05)$ entre os membros torácicos e pélvicos quanto às características pesquisadas no LS da BTD. O número de amostras analisadas por característica variou em função do volume de LS, obtido na punção, e da ocorrência de coagulação.

Obteve-se LS em 83,3\% das punções realizadas na BTD. Nas 30 amostras colhidas houve predomínio do aspecto amarelo claro, límpido e ausência de partículas em suspensão. Duas amostras foram contaminadas com sangue durante a punção da bainha, o que, segundo Boon (1997), é comum, em conseqüência da ruptura de capilares subsinoviais (Van Pelt, 1974) e essa pôde ser confirmada pela inexistência de amostras com coloração alterada no início da punção (Parry, 1999) e ausência de xantocromia após sua centrifugação (Van Pelt, 1962; Mahaffey, 1992; Parry, 1999). Essas amostras apresentavam-se avermelhadas e coagularam à temperatura ambiente.

A viscosidade (mediana \pm erro-padrão: $2 \pm 0,09$; onde $2=$ normal) do LS foi normal em $70 \%$ das
30 amostras e diminuída nas restantes. Correlação negativa $(\mathrm{r}=-0,489 ; \quad \mathrm{P}<0,01)$ foi verificada entre a viscosidade e o volume de LS aspirado, atribuída à diluição da concentração de AH (Van Pelt, 1962; Tew e Hotchkiss, 1981).

Os coágulos de mucina (mediana \pm erro-padrão: $2 \pm 0,11$; onde $2=$ regular) formados nas 22 amostras de LS foram classificados como bons em 45,5\% das análises e como regulares nas demais. A formação desses tipos de coágulo em amostras de LS obtidas de eqüinos sadios também foi relatada por Van Pelt (1962) e pode ser explicada pelas diferenças quantitativas ou qualitativas de proteínas totais (Rowley et al., 1982; McIlwraith, 1987) e AH de cada uma delas, pois ambas as substâncias atuam na formação do coágulo. Correlação positiva $(\mathrm{r}=0,760 ; \quad \mathrm{P}<0,01)$ foi verificada entre $\mathrm{a}$ qualidade do coágulo de mucina e a viscosidade do LS, atribuída à influência exercida pela quantidade e qualidade do $\mathrm{AH}$ presente na amostra (Van Pelt 1962; 1967).

Volume, densidade e características químicas e citológicas do LS da BTD dos eqüinos encontram-se na Tab. 1.

Tabela 1. Número de amostras, médias, erros padrão e valores limite para volume, densidade e características químicas e citológicas do líquido sinovial da bainha tendínea digital de eqüinos hígidos

\begin{tabular}{|c|c|c|c|}
\hline Variável & $\begin{array}{c}\mathrm{N}^{0} \cdot \text { de } \\
\text { amostras }\end{array}$ & $\begin{array}{c}\text { Média } \pm \\
\text { erro-padrão }\end{array}$ & Valores limite \\
\hline Volume (ml) & 30 & $1,95 \pm 0,18$ & $0,20-4,00$ \\
\hline Densidade & 30 & $1,014 \pm 0,001$ & $1,010-1,021$ \\
\hline Glicose $(\mathrm{mg} / \mathrm{dl})$ & 29 & $98,23 \pm 2,67$ & $70,20-125,50$ \\
\hline Ácido hialurônico (mg/dl) & 28 & $60,20 \pm 4,26$ & $15,65-113,33$ \\
\hline Proteínas totais $(\mathrm{g} / \mathrm{dl})$ & 30 & $1,15 \pm 0,05$ & $0,60-1,74$ \\
\hline Relação A:G & 22 & $0,94 \pm 0,11$ & $0,41-2,84$ \\
\hline FA (U/1) & 28 & $28,06 \pm 1,56$ & $8,20-49,70$ \\
\hline AST $(\mathrm{U} / \mathrm{ml})$ & 29 & $56,17 \pm 2,29$ & $36,67-83,81$ \\
\hline Hemácias (células $/ \mu \mathrm{l})$ & 25 & $6.714 \pm 1.370$ & $400-24.140$ \\
\hline Células nucleadas $(/ \mu \mathrm{l})$ & 25 & $313 \pm 98$ & $0-1.640$ \\
\hline Neutrófilos segmentados (\%) & 25 & $1,90 \pm 0,33$ & $0-6$ \\
\hline Linfócitos $(\%)$ & 25 & $32,42 \pm 4,77$ & $3-83$ \\
\hline Grandes células mononucleares (\%) & 25 & $65,56 \pm 4,76$ & $16-96$ \\
\hline Eosinófilos (\%) & 25 & $0,12 \pm 0,07$ & $0-1$ \\
\hline
\end{tabular}

Verificaram-se correlações positivas entre densidade e concentrações de ácido hialurônico $(\mathrm{r}=0,410 ; \mathrm{P}<0,05)$ e de proteínas totais $(\mathrm{r}=0,404$;
$\mathrm{P}<0,05)$ no LS, explicadas pela presença dessas substâncias no fluido. Observou-se correlação negativa entre a densidade e o volume aspirado 
$(\mathrm{r}=-0,456 ; \mathrm{P}<0,05)$, justificada pela diferença de diluição do $\mathrm{AH}$ e das proteínas na solução.

A concentração média de glicose no LS foi 7,1\% maior que a plasmática, sendo consideradas similares, conforme descrito por Curtiss (1964) e Van Pelt (1974). A correlação entre as concentrações de glicose no LS e no plasma foi positiva $(\mathrm{r}=0,696 ; \mathrm{P}<0,01)$, atribuída à tendência de equilíbrio existente em condições normais, permitida pela livre difusão desta substância através da membrana sinovial (Mahaffey, 1992). O jejum a que os animais foram submetidos é requerido para que ocorra o equilíbrio entre as concentrações desse açúcar nos compartimentos sinovial e sangüíneo, pois, conforme Zeller et al. (1941), alterações na concentração de glicose no LS são passíveis de atraso em relação a exacerbações ou remissões de sua concentração plasmática. Além disso, sua taxa de difusão pela barreira sangue-membrana sinovial, aparentemente, não é rápida o suficiente para manutenção do equilíbrio dinâmico (Van Pelt, 1962). Não se observou correlação $(P>0,05)$ entre a concentração de glicose e a contagem eritrocitária do LS.

Observou-se correlação negativa entre a concentração de AH $(\mathrm{r}=-0,395 ; \mathrm{P}<0,05)$ e $\mathrm{o}$ volume de LS aspirado, justificada pela menor diluição desse composto em virtude do volume líquido reduzido (Van Pelt, 1962). As correlações positivas verificadas entre a quantidade de $\mathrm{AH}$ e a viscosidade $(\mathrm{r}=0,713$; $\mathrm{P}<0,01)$ e entre a primeira e a QPM $(\mathrm{r}=0,701$; $\mathrm{P}<0,01)$ eram esperadas, pois essas últimas características refletem a quantidade e a qualidade do hialuronato do LS. Observou-se correlação negativa entre a concentração de $\mathrm{AH}$ e a porcentagem de linfócitos $(\mathrm{r}=-0,649 ; \mathrm{P}<0,01)$ no LS, atribuída à ação inibitória do hialuronato sobre a migração de linfócitos para a cavidade sinovial. Sua concentração e forma tridimensional levam à exclusão estereométrica desses leucócitos, sugerindo efeito antiinflamatório do AH (McIlwraith, 1997).

A concentração de proteínas no LS correspondeu, em média, a $16,2 \%$ de sua concentração sérica. A relação $\mathrm{A}: \mathrm{G}$ no $\mathrm{LS}$ foi maior que a do sangue nos animais estudados, confirmando os relatos de Curtiss (1964) e Van Pelt (1967), que afirmaram que o LS normal apresenta proporcionalmente mais albumina que o sangue, devido à diferença de peso molecular de ambas (Jones et al., 1993), refletindo-se na permeabilidade seletiva da membrana sinovial a compostos de alto peso molecular, como é o caso das várias frações globulínicas.

Embora a atividade média da AST no LS verificada neste experimento seja menor que a sérica, esse valor pode estar discretamente superestimado, pois houve correlação positiva entre AST e o número de hemácias $(\mathrm{r}=0,439$; $\mathrm{P}<0,05)$ presentes na amostra, condizente com a liberação da enzima por estas células. Kramer e Hoffmann (1997) descreveram a existência de AST nos eritrócitos e a sua liberação no plasma antes da hemólise. Observou-se correlação positiva entre a atividade da AST e a porcentagem de neutrófilos segmentados $(\mathrm{r}=0,414 ; \mathrm{P}<0,05)$ no $\mathrm{LS}$, o que também foi descrito por Curtiss (1964) em relação ao conteúdo leucocitário, e verificado, indiretamente, por McIlwraith (1987) pela correlação positiva entre o número de leucócitos no campo microscópico e os níveis enzimáticos. As correlações são explicadas pela liberação de AST pelos neutrófilos segmentados, gerando uma proporção direta entre o seu número nas amostras sinoviais e a atividade enzimática.

Neste ensaio, o número de hemácias nas amostras de LS variou consideravelmente (Tab. 1), sendo imputado à contaminação da amostra de LS no momento da punção, ainda que não tenha sido notada visualmente. $\mathrm{O}$ valor médio da contagem global de $\mathrm{CN}$ manteve-se entre aqueles considerados normais para o LS (Van Pelt, 1967, 1974; Tew e Hotchkiss, 1981; Malark et al., 1991). As grandes células mononucleares predominaram, seguidas pelos linfócitos, neutrófilos segmentados e eosinófilos. Algumas amostras apresentaram inversão de predominância entre as grandes células mononucleares e os linfócitos, mas ambos os tipos celulares sempre foram os mais abundantes. A variação pode estar fundamentada na influência que a concentração e o grau de polimerização da molécula de $\mathrm{AH}$ exercem sobre a migração linfocitária para a cavidade sinovial, sem que certa alteração na concentração de hialuronato no LS modifique características peculiares de normalidade desse fluido.

As alterações patológicas decorrentes da tenossinovite, provavelmente, se manifestam 
precocemente no LS, como descrito nos processos articulares por Tulamo et al. (1989), alterando sua composição físico-química e citológica antes que outros sintomas clínicos apareçam. Assim, uma vez conhecidos os valores de referência para o LS da BTD dos eqüinos, sua análise provê informações que agilizam o diagnóstico (Barnabé, 2001; Barnabé et al., 2004), podendo ajudar no estabelecimento do grau de severidade das lesões associadas a essas estruturas, propiciando elementos dinâmicos para reavaliações de casos clínicos e prognóstico mais acurado.

\section{CONCLUSÕES}

As mensurações das características pesquisadas no LS da BTD de eqüinos são de execução simples e passíveis de implantação na rotina de atendimentos clínico-cirúrgicos, podendo trazer contribuição significativa ao diagnóstico, tratamento e prognóstico de animais com alterações patológicas da BTD. A contaminação de amostras de LS com pequena quantidade de sangue não ocasiona prejuízos a sua análise.

\section{REFERÊNCIAS BIBLIOGRÁFICAS}

BARNABÉ, P.A. Estudo de características físico-químicas e citológicas do líquido sinovial da bainha tendínea digital de eqüinos. 2001. 96f. Dissertação (Mestrado em Cirurgia Veterinária) - Faculdade de Ciências Agrárias e Veterinárias, Universidade Estadual Paulista, Jaboticabal.

BARNABÉ, P.A.; CATTELAN, J.W.; CADIOLI, F.A. Anatomofisiologia da bainha tendínea sinovial digital dos eqüinos. Ciên. Rural, v.34, p.619-623, 2004.

BERTONE, A.L. Infectious tenosynovitis. Vet. Clin. North. Am.: Equine Pract., v.11, p.163176, 1995

BOON, G.D. Synovial fluid analysis: a guide for small-animal practitioners. Vet. Med., v.92, p.443-451, 1997.

BRADFORD, M.M. A rapid and sensitive method for the quantitation of microgram quantities of protein utilizing the principle of protein-dye binding. Anal. Biochem., v.72, p.248-254, 1976.
CURTISS, P.H. Changes produced in the synovial membrane and synovial fluid by disease. J. Bone Jt. Surg., v.46-A, p.873-878, 1964.

HONNAS, C.M.; SCHUMACHER, J.; COHEN, N.D. et al. Septic tenosynovitis in horses: 25 cases (1983- 1989). J. Am. Vet. Med. Assoc., v.199, p.1616-1622, 1991.

JONES, D.L.; BARBER, S.M.; DOIGE, C.E. Synovial fluid and clinical changes after arthroscopic partial synovectomy of the equine middle carpal joint. Vet. Surg., v.22, p.524-530, 1993.

KANEKO, J.J.; HARVEY, J.W.; BRUSS, M.L. (Eds.). Clinical biochemistry of domestic animals. 5.ed. San Diego: Academic, 1997. p.890-894.

KRAMER, J.W.; HOFFMANN, W.E. Clinical enzymology. In: KANEKO, J.J.; HARVEY, J.W.; BRUSS, M.L. (Eds.). Clinical biochemistry of domestic animals. 5.ed. San Diego: Academic, 1997. p.303-325.

LITTLE, C.B.; HILBERT, B.J.; WICKSTROM, S. et al. Quantitative microanalysis of equine synovial fluid glicosaminoglycan concentration. Am. J. Vet. Res., v.51, p.1534-1539, 1990.

MAHAFFEY, E.A. Synovial fluid. In: COWELL, R.L.; TYLER, R.D. (Eds.). Cytology and hematology of the horse. Goleta: American Veterinary, 1992. p.153-161.

MALARK, J.A.; NIXON, A.J.; SKINNER, K.L. et al. Characteristics of digital flexor tendon sheath fluid from clinically normal horses. Am. J. Vet. Res., v.52, p.1292-1294, 1991.

McILWRAITH, C.W. Diseases of joints, tendons, ligaments, and related structures. In: STASHAK, T.S. (Ed). Adams' lameness in horses. 4.ed. Philadelphia: Lea \& Febiger, 1987. p.339-485.

McILWRAITH, C.W. Use of sodium hyaluronate (hyaluronan) in equine joint disease. Equine Vet. Educ., v.9, p.296-304, 1997.

MOYER, W. Clinical use of synovial fluid analysis. In: ANNUAL CONVENTION OF THE AMERICAN ASSOCIATION OF EQUINE PRACTITIONERS, 28., 1982, Georgia. Proceedings... [s.1.]: American Association of Equine Practitioners, 1983. p.129-135. 
PARRY, B.W. Synovial fluid. In: COWELL, R.L.; TYLER, R.D.; MEINKOTH, J.H. (Eds.). Diagnostic cytology and hematology of the dog and cat. 2.ed. St. Louis: Mosby, 1999. p.104119.

ROWLEY, G.; ANTONAS, K.N.; HILBERT, B.J. Quantitation of hyaluronic acid in equine synovia. Am. J. Vet. Res., v.43, p.1096-1099, 1982.

TEW, W.P.; HOTCHKISS, R.N. Synovial fluid analysis and equine joint disorders. J. Equine Vet. Sci., v.1, p.163-170, 1981.

TROTTER, G.W.; McILWRAITH, C.W. Clinical features and diagnosis of equine joint disease. In: McILWRAITH, C.W; TROTTER, G.W. (Eds.). Joint disease in the horse. Philadelphia: WB Saunders, 1996. p.120-145.

TULAMO, R.M.; BRAMLAGE, L.R.; GABEL, A.A. Sequential clinical and synovial fluid changes associated with acute infectious arthritis in the horse. Equine Vet. J., v.21, p.325-331, 1989.

USER'S guide: statistics. Version 6.12, 4.ed. Cary, NC: SAS Institute Inc., 1999. v.1.

VAN PELT, R.W. Characteristics of normal equine tarsal synovial fluid. Can. J. Comp. Med. Vet. Sci., v.31, p.342-347, 1967.

VAN PELT, R.W. Interpretation of synovial fluid findings in the horse. J. Am. Vet. Med. Assoc., v.165, p.91-95, 1974.

VAN PELT, R.W. Properties of equine synovial fluid. J. Am. Vet. Med. Assoc., v.141, p.10511061, 1962.

ZELLER, J.W.; BYWATERS, E.G.L.; BAUER, $\mathrm{W}$. The passage of thiocyanate and glucose from the blood stream into the joint spaces. Am. J. Physiol., v.132, p.150-156, 1941. 